\title{
Editorial \\ Stress of different types increases the proinflammatory load in rheumatoid arthritis
}

\author{
Rainer H Straub ${ }^{1}$ and Joachim R Kalden²
}

\author{
${ }^{1}$ Laboratory of Experimental Rheumatology and Neuroendocrino-Immunology, Division of Rheumatology, Department of Internal Medicine I, University \\ Hospital, 93042 Regensburg, Germany \\ ${ }^{2}$ Department of Medicine 3, University of Erlangen-Nuremberg, Nikolaus-Fiebiger-Center, 91054 Erlangen, Germany
}

Corresponding author: Rainer H Straub, rainer.straub@klinik.uni-regensburg.de

Published: 17 June 2009

Arthritis Research \& Therapy 2009, 11:114 (doi:10.1186/ar2712)

This article is online at http://arthritis-research.com/content/11/3/114

(c) 2009 BioMed Central Ltd

See related research by Edwards et al., http://arthritis-research.com/content/11/3/R61

\begin{abstract}
Stress in patients with chronic inflammatory diseases such as rheumatoid arthritis (RA) stimulates proinflammatory mechanisms due to the defect of stress response systems (for example, the sympathetic nervous system and the hypothalamic-pituitaryadrenal axis). Among other mechanisms, the loss of sympathetic nerve fibers in inflamed tissue and inadequate cortisol secretion in relation to inflammation lead to an enhanced proinflammatory load in RA. Stress and the subsequent stimulation of inflammation (systemic and local) lead to increased sensitization of pain and further defects of stress response systems (vicious cycle of stress, pain, and inflammation).
\end{abstract}

In 1937 Hans Selye called the activation of stress systems an 'alarm reaction', which is the reaction of an organism 'when first confronted with a stimulus to which it is quantitatively or qualitatively not adapted'. Until the beginning of the 1980s, the stress systems including the sympathetic nervous system (SNS) and the hypothalamic-pituitary-adrenal axis were thought to play a proinflammatory role by supporting the immune response. This view was markedly changed in the years thereafter, when targeted experiments with specific immune cells involving hormones of the SNS and hypothalamic-pituitary-adrenal axis were carried out using cell culture. These results demonstrated that noradrenaline (via $\beta_{2}$-adrenoceptors at $10^{-6} \mathrm{M}$ ) and cortisol (via glucocorticoid receptor $\alpha$ ) exert many anti-inflammatory effects. Today we know that both proinflammatory and anti-inflammatory effects can appear under stressful conditions, which depend on the duration of the stress, the intensity of stress, the perception of stress (whether positive or negative), the environmental milieu within the body of the stressed person (whether acutely ill or chronically ill), and the time point of stress in relation to the outbreak of a chronic inflammatory disease (whether before outbreak or in later phases of the symptomatic disease). Knowledge in the stress field steadily increases, and today we can say that patients with chronic inflammatory diseases such as rheumatoid arthritis (RA) show abnormal stress responses leading to proinflammatory consequences.

Stress can be induced by pain tests, which was recently demonstrated by Edwards and colleagues [1]. In this study the authors used several pain tests, such as the pressure pain threshold, the heat pain threshold, and the cold pressor task. The patients with RA, compared with healthy control individuals, had lower mechanical pain thresholds, lower heat pain thresholds, and lower cold pain tolerance, all of which are expected in a situation with peripheral sensitization to noxious stimuli [2]. Indeed, peripheral sensitization has been demonstrated several times in RA patients [2]. The important and original aspect of the work of Edwards and colleagues is the fact that pain testing increased serum levels of TNF, which was not demonstrated in healthy control individuals. The increase was slow over the entire observation time without decline. A similar trend was observed for serum IL-6 [1]. This effect is interpreted as an unwanted deleterious effect that can shape the long-term symptomatology in RA.

Edwards and colleagues' paper adds nicely to existing literature where, after stress testing, other groups demonstrated a very similar effect on serum or supernatant levels (in cell culture experiments) of proinflammatory cytokines (Table 1). Since stress in healthy subjects can lead to an increase of serum cytokines [3], a comparison of patients with RA and healthy control individuals is mandatory. The important aspect in the studies demonstrated in Table 1 is the fact that respective control groups did not show a similar increase of inflammation markers. Form this point of view, the

$\mathrm{IL}=$ interleukin; $\mathrm{RA}=$ rheumatoid arthritis; $\mathrm{SNS}=$ sympathetic nervous system; TNF $=$ tumor necrosis factor. 
Table 1

Stress leads to an increase of proinflammatory factors in rheumatoid arthritis

\begin{tabular}{lll}
\hline Stress & Cytokine and response & Reference \\
\hline Cold pressor test & Increase of stimulated IL-6 in cell culture (via $\alpha_{1}$-adrenergic receptors) & [6] \\
Stress before surgery & Increase of serum IL-6 & [7] \\
Mental stress task & Increase of serum C-reactive protein & [9] \\
Mental stress task & Increase of stimulated TNF in cell culture & [10] \\
Acute whole body cold stress & Increase of serum IL-6 & I1] \\
Pain stress & Increase of serum TNF (trend for IL-6) \\
\hline
\end{tabular}

tested RA patients demonstrate a markedly different situation. We recently summarized the various arguments and concluded that stress increases the proinflammatory load in patients with RA because the stress response systems are defective [4].

For example, it has been demonstrated that sympathetic nerve fibers are lost in inflamed tissue of patients with RA (reviewed in [4]). In parallel, sensory nerve fibers containing the major proinflammatory neuropeptide substance $P$ sprout into inflamed tissue (reviewed in [4]). Since application of noradrenaline at high concentrations $\left(10^{-6} \mathrm{M}\right)$ via $\beta_{2}$-adrenoceptors is anti-inflammatory by strongly inhibiting TNF, the loss of sympathetic nerve fibers in inflamed tissue of RA patients leads to a proinflammatory situation (TNF is stimulated via substance $P$ receptors and $\alpha$-adrenoceptors at low noradrenaline concentrations of $\left.10^{-8} \mathrm{M}\right)$. The balance between the nociceptive system (substance P) and the SNS (noradrenaline) is shifted to the proinflammatory site. Under a situation of stress, the usual anti-inflammatory influence of the SNS is no longer functional because of the dramatic loss of sympathetic nerve fibers.

Similar arguments exist for the hypothalamic-pituitaryadrenal axis, where stress tests in RA patients demonstrated a decreased stress response. Dekkers and colleagues have demonstrated that RA patients, as compared with control individuals, do not mount a significant adrenocorticotropic hormone response upon controlled psychological stress, which is also visible in the form of an inadequate cortisol secretion during the test phase [5]. It has been demonstrated that controlled exercise-induced release of cortisol was markedly decreased in patients with RA as compared with control individuals (reviewed in [4]). The usual anti-inflammatory cortisol response is therefore inadequately low in relation to inflammation, particularly, in stressed RA patients.

In conclusion, under chronic inflammatory conditions we observe defects of the stress axes with inadequate secretion of cortisol and a functional loss of synovial sympathetic nerve fibers, which generate the basis for stress-induced aggravation of the disease. Elevated local or systemic levels of proinflammatory cytokines stimulate a vicious cycle of increased pain most probably relevant for peripheral and central sensitization.

\section{Competing interests}

The authors declare that they have no competing interests.

\section{References}

1. Edwards RR, Wasan AD, Bingham III CO, Bathon J, Haythornthwaite JA, Smith MT, Page GG: Enhanced reactivity to pain in patients with rheumatoid arthritis. Arthritis Res Ther 2009, 11: R61.

2. Schaible HG, Del RA, Matucci-Cerinic M: Neurogenic aspects of inflammation. Rheum Dis Clin North Am 2005, 31:77-101.

3. Steptoe A, Hamer M, Chida Y: The effects of acute psychological stress on circulating inflammatory factors in humans: a review and meta-analysis. Brain Behav Immun 2007, 21:901912.

4. Straub RH, Dhabhar FS, Bijlsma JW, Cutolo M: How psychological stress via hormones and nerve fibers may exacerbate rheumatoid arthritis. Arthritis Rheum 2005, 52:16-26.

5. Dekkers JC, Geenen R, Godaert GL, Glaudemans KA, Lafeber FP, van Doornen LJ, Bijlsma JW: Experimentally challenged reactivity of the hypothalamic pituitary adrenal axis in patients with recently diagnosed rheumatoid arthritis. I Rheumatol 2001, 28:1496-1504.

6. Roupe van der Voort C, Heijnen CJ, Wulffraat N, Kuis W, Kavelaars A: Stress induces increases in IL- 6 production by leucocytes of patients with the chronic inflammatory disease juvenile rheumatoid arthritis: a putative role for alpha(1)adrenergic receptors. J Neuroimmunol 2000, 110:223-229.

7. Hirano D, Nagashima M, Ogawa R, Yoshino S: Serum levels of interleukin 6 and stress related substances indicate mental stress condition in patients with rheumatoid arthritis. J Rheumatol 2001, 28:490-495.

8. Veldhuijzen van Zanten JJ, Ring C, Carroll D, Kitas GD: Increased $C$ reactive protein in response to acute stress in patients with rheumatoid arthritis. Ann Rheum Dis 2005, 64:1299-1304.

9. Motivala SJ, Khanna D, FitzGerald J, Irwin MR: Stress activation of cellular markers of inflammation in rheumatoid arthritis: protective effects of tumor necrosis factor alpha antagonists. Arthritis Rheum 2008, 58:376-383.

10. Straub RH, Pongratz G, Hirvonen H, Pohjolainen T, Mikkelsson M, Leirisalo-Repo M: Acute cold stress in rheumatoid arthritis inadequately activates stress responses and induces an increase of interleukin 6. Ann Rheum Dis 2009, 68:572-578. 